\title{
Analysis and Evaluation of the North Oil Companies
}

\author{
*Muayad Hassan Marei al-gburi, ** Salah al-Din Awwad Karim al-Kubaisi \\ * North Oil Company, Kirkuk / Iraq \\ ** College of Administration and Economics, University of Baghdad, Baghdad, Iraq
}

DOI: $10.37648 / \mathrm{ijrssh.v10i03.040}$

Received: 24 ${ }^{\text {th }}$ July, 2020; Accepted: 29th August, 2020; Published: 09th September,2020

\begin{abstract}
This research aims to analyze and evaluate the proposed strategic document in the North Oil Company for the years (20202024) by presenting it to a sample consisting of (20) individuals deliberately chosen and they are among the most important senior leaders in the company from managers of bodies and departments and experts in the field of management and operation The oil companies for the purpose of analyzing and evaluating them, and the proposed strategy took into account the surrounding environmental conditions and adopted in its formulation on the basis and scientific steps that are comprehensive and realistic, as they covered the main activities in the company and considering that the members of the sample are the most in line with the paragraphs and programs of the proposed strategic plan, as they are responsible for implementation Accordingly, they are the most able to evaluate this document and diagnose its strengths and weaknesses. A questionnaire was designed from (16) paragraphs that included the strategic factors and dimensions of the proposed document as a main tool for obtaining the data that were designed according to Likert's five-point scale (strongly agree strongly disagree), The two researchers used (the arithmetic mean, the standard deviation) in analyzing the data taken from the research sample, and the results of the study concluded that the rate of acceptability and conviction For the managers and decision-makers in the company, the proposed document is (80\%), which is a reasonable and acceptable percentage that gives a very good indication "of the formulated strategic document.
\end{abstract}

\section{INTRODUCTION:}

The business environment in our world today has been characterized by continuous fluctuations and high dynamism as a result of developments in various political, technological, economic and social aspects, which forced the adoption of the concept of strategic management and strategic planning to adapt to these rapid changes in environmental factors. Therefore, strategic planning ensures that organizations achieve success as it makes business and jobs More flexible and clear, and therefore it was necessary to conduct an analysis and evaluation of the plans and strategies proposed for the company to find out the appropriate mechanism for its implementation and diagnose the defect, if any. Appropriate solutions and therefore this research came.

\section{THE FIRST AXIS: RESEARCH METHODOLOGY}

\subsection{Research Problem:}

The research problem is reflected in an important question, which is: Is the proposed strategy in the North Oil Company appropriate to the reality of the company 
and commensurate with the current conditions of the company and meet the aspiration of workers to achieve development and prosperity for their company.

\subsection{Importance of research:}

The importance of the research lies in obtaining accurate and very important information and data about the proposed strategy. The results of the research contribute to strengthening the plot and sobriety of the proposed strategic plan and its evaluation.

\subsection{A description of the study community}

The North Oil Company is one of the formations of the Iraqi Ministry of Oil and it is one of the extractive oil companies. Its main activity is the production of crude oil and natural gas from the oil fields located in the northern part of Iraq, and among the most important and largest fields managed by the company are: the Kirkuk field, the Bay Hassan field, the Hamrin field, the Jumpur field, the Khabaz field, as well as several other medium and small fields such as (Ajil, Qayyarah, and Safia).

\section{THE SECOND AXIS: THE THEORETICAL SIDE}

\subsection{Concept of strategy formulation}

It is a guide for executives in determining the actions of their organizations to reach their goals and the means that will be used to achieve those goals (Emeka et al, 2015: 12). According to( Belyh, 2017: 3) it is the process of defining and establishing the goals, mission and objectives of the organization, and identifying the appropriate and best courses or action plans among all the alternative strategies available to achieve them. (Wheelen, et al, 2018: 47) describes it as a process of investigation, analysis and decision-making that provides the company with criteria for obtaining a competitive advantage and includes identifying the competitive advantages of the company, identifying weaknesses that affect the company's ability to grow, formulating the mission of the organization, setting goals. Attainable, and set policy guidelines. (Bolisani \& Bratianu, 2018: 5) went on to say that it is a clear and regular process aimed at formulating the "official strategy" of the organization, which is carried out periodically and "rationally", and depends on organized plans and procedures that guide the decision-making process. In an explanation of strategy formulation, (AlAmiri and Al-Ghalibi, 2011: 268) says that the precise meaning of strategy formulation is the totality of the processes by which strategies are created or constructed, and this includes evaluating current strategies and evaluating the organization's situation and environment with the aim of developing subsequent strategies also capable of creating future competitive advantages. . Within the general framework, the strategy formulation processes have been adopted through an objective and practical analysis of options and the development of the necessary plans and their implementation to support the organization's specific objectives, and thus deliberate strategies are called (Deliberate Strategy), while some organizations appear to have specific strategic options and their development in the absence and lack of clarity of their mission and objectives. The term and these strategies are called (Emergent Strategies), meaning emergency strategies, and some researchers call them emerging strategies based on experiences that depend mainly on the experience of the managers and leaders of the organization, and both strategies represent the business organization's desire to adopt a strategy that focuses on the use of maximum organizational synergies in which efforts can be unified to achieve goals and represent These are bottom-line strategies called( intent strategy).

\subsection{The objectives of strategy formulation}

Strategic planning is concerned with formulating strategy and adds (Bryson, 2004: 6) and its purpose is to enhance strategic thinking, adaptation and learning continuously, and therefore strategic planning takes a (big picture) approach that mixes future thinking with objective analysis and self-evaluation of values, goals and priorities in order to chart the future direction. And work streams to ensure the organization's vitality, effectiveness and ability to create added value. As for (Al-Damour, 2008: 2), he says that strategic planning is one of the modern administrative concepts and an effective tool to achieve long-term goals because it allows organizations to define their current and future 
capabilities in a way that guarantees success in a world characterized by constant change and dynamism, as it requires an effective use of planning in all organizations and Its various activities. (Poister ,2010: 246) went on to link the objectives of strategic planning and strategy formulation to achieve the efficiency of managing the overall performance of the organization and says: For the purpose of formulating the strategy to be more useful in the future requires moving after strategic planning to the broader process of strategic management, which involves managing the overall strategic agenda of the organization On an ongoing basis, not accidental, to ensure effective implementation of strategies and focus more proactively on achieving strategic goals and objectives, organizations need to link their strategic plan and performance management processes more closely and continuously in a reciprocal relationship in which the strategic plan aims to define and enhance overall performance and in return, performance monitoring helps to enrich the strategy .

\subsection{Principles of strategy formulation}

(Markides, 1999: 3) suggested basic principles on which each penetration strategy is based, which is choosing a unique strategic position for the organization. The strategy must first generate the largest possible number of options to reach the desired strategic location, and these options must be clear and can be combined to build a combination of options. Strong and suited to the combination of the organization's environment without sacrificing the flexibility of the strategic plan. (Khader ,2016: 3) states that the formulation of the strategy depends on several principles, including setting and specifying all the goals to be achieved, ensuring that the strategy is characterized by flexibility and ease of application in the work environment, that the strategy is comprehensive and integrated, meaning that no part is overlooked The plan to be implemented. In this aspect (Albu \& Krist, 2017: 3) says, we have realized the value of some guiding principles that can be used by leadership teams when formulating and implementing the strategy, namely: Focusing on the most important, as setting priorities is an important step in achieving the strategy's objectives. Changing the basic activity of the organization and investing and developing the current competitive advantages, communicating to ensure that every person in the organization understands the goals of the plan and understands his role in it, moral encouragement to create a pace of progress to increase the momentum to keep everyone interested and committed, flexibility, strategy formulation is a dynamic and continuous process, and making adjustments is an option., Investing in foreign aid, a foreign agency prepared to assist financially, technically, or in an advisory capacity.

\section{THE THIRD AXIS: THE PRACTICAL SIDE}

\subsection{Results of the evaluation of the proposed strategic document}

The questionnaire that was designed for the purpose of evaluating the proposed strategic document of (16) paragraphs included the strategic factors and dimensions of the proposed document. The opinions of a sample consisting of (20) managers and experts in the company were surveyed to whom the proposed document was presented for the purpose of evaluating it and expressing their opinion of its contents. Being in direct contact with the formulation and implementation of the strategy, as the questionnaire is based on the five-year Likert scale (Strongly agree - Strongly disagree) and the level of sample agreement is determined by relying on the arithmetic mean according to the categories and the level of each variable will be between (1-5), so that $5=$ Strongly agree, $1=$ Strongly disagree) The result of the arithmetic mean will be interpreted according to the length of the category that was calculated, as the range is calculated and equals 5-1 = 4 then the category length is calculated by dividing the range by the number of categories (options) $4 / 5=0.80$. So the first category of the mean values is: from 1 to $1+0.80=1.80$, as the arithmetic averages are as follows: (from 1 to 1.80 strongly disagree), (from 1.81 to 2.60 not agree), (from 2.61 to 3.40 Neutral), (from 3.41 to 4.20 agree), (from 4.21 to 5.00 strongly agree) (Joshi at el, 2015: 396), and Table (1) shows the evaluation results as follows: 
Table (1) Frequencies, percentages, arithmetic mean and standard deviation of the paragraphs of the proposed strategy

\begin{tabular}{|c|c|c|c|c|c|c|c|c|c|c|c|c|c|}
\hline \multirow[t]{2}{*}{$\begin{array}{l}\text { standard } \\
\text { deviatio } \\
\text { n }\end{array}$} & \multirow[t]{2}{*}{$\begin{array}{l}\text { Arithm } \\
\text { etic } \\
\text { mean }\end{array}$} & \multicolumn{2}{|c|}{$\begin{array}{l}\text { I totally } \\
\text { agree } \\
5\end{array}$} & \multicolumn{2}{|c|}{$\begin{array}{l}\text { I agree } \\
4\end{array}$} & \multicolumn{2}{|c|}{$\begin{array}{l}\text { Neutral } \\
3\end{array}$} & \multicolumn{2}{|c|}{$\begin{array}{l}\text { I do not } \\
\text { agree } \\
2\end{array}$} & \multicolumn{2}{|c|}{$\begin{array}{l}\text { Strongly } \\
\text { Disagree } \\
1\end{array}$} & \multirow[t]{2}{*}{ The Worker } & \multirow[t]{2}{*}{ d } \\
\hline & & $\%$ & $d$ & $\%$ & $\bar{d}$ & $\%$ & $\bar{d}$ & $\%$ & $\mathbf{d}$ & $\%$ & $\bar{d}$ & & \\
\hline 0.63 & 4.25 & $35 \%$ & 7 & $55 \%$ & 11 & $10 \%$ & 2 & 0.00 & $\mathbf{0}$ & 0.00 & $\mathbf{0}$ & $\begin{array}{l}\text { Strategic } \\
\text { analysis }\end{array}$ & 1 \\
\hline 0.68 & 4,05 & $25 \%$ & 5 & $55 \%$ & 11 & $20 \%$ & 4 & 0.00 & $\mathbf{0}$ & 0.00 & $\mathbf{0}$ & Vision & 2 \\
\hline 0.64 & 4.00 & $20 \%$ & 4 & $60 \%$ & 12 & $20 \%$ & 4 & 0.00 & $\mathbf{0}$ & 0.00 & $\mathbf{0}$ & the message & 3 \\
\hline 0.78 & 3.90 & $25 \%$ & 5 & $40 \%$ & 8 & $35 \%$ & 7 & 0.00 & $\mathbf{0}$ & 0.00 & $\mathbf{0}$ & Values & 4 \\
\hline 0.67 & 4.15 & $30 \%$ & 6 & $55 \%$ & 11 & $15 \%$ & 3 & 0.00 & $\mathbf{0}$ & 0.00 & $\mathbf{0}$ & strategic goals & 5 \\
\hline 0.69 & 4.20 & $35 \%$ & \begin{tabular}{|l|}
7 \\
\end{tabular} & $\mathbf{5 0 \%}$ & 10 & $15 \%$ & 3 & 0.00 & $\mathbf{0}$ & 0.00 & $\mathbf{0}$ & Strategic issues & 6 \\
\hline 0.64 & 4.00 & $20 \%$ & 4 & $60 \%$ & 12 & $20 \%$ & 4 & 0.00 & $\mathbf{0}$ & 0.00 & $\mathbf{0}$ & Time span & 7 \\
\hline 0.73 & 4.30 & $45 \%$ & 9 & $40 \%$ & 8 & $15 \%$ & 3 & 0.00 & $\mathbf{0}$ & 0.00 & 0 & $\begin{array}{l}\text { Strategic } \\
\text { alternatives }\end{array}$ & 8 \\
\hline 0.71 & 3.90 & $20 \%$ & 4 & $50 \%$ & 10 & $30 \%$ & 6 & 0.00 & $\mathbf{0}$ & 0.00 & $\mathbf{0}$ & Constraints & 9 \\
\hline 0.71 & 4.10 & $30 \%$ & 6 & $50 \%$ & 10 & $20 \%$ & 4 & 0.00 & $\mathbf{0}$ & 0.00 & $\mathbf{0}$ & Programs & 10 \\
\hline 0.71 & 3.90 & $20 \%$ & 4 & $50 \%$ & 10 & $30 \%$ & 6 & 0.00 & $\mathbf{0}$ & 0.00 & $\mathbf{0}$ & Measures & 11 \\
\hline 0.71 & 3.90 & $20 \%$ & 4 & $50 \%$ & 10 & $30 \%$ & 6 & 0.00 & $\mathbf{0}$ & 0.00 & 0 & $\begin{array}{l}\text { Indicators of } \\
\text { success }\end{array}$ & 12 \\
\hline 0.64 & 3.90 & $15 \%$ & 3 & $60 \%$ & 12 & $25 \%$ & 5 & 0.00 & 0 & 0.00 & $\mathbf{0}$ & $\begin{array}{l}\text { Flexibility and } \\
\text { responsivenes }\end{array}$ & 13 \\
\hline 0.71 & 4.10 & $30 \%$ & 6 & $50 \%$ & 10 & $20 \%$ & 4 & 0.00 & $\mathbf{0}$ & 0.00 & $\mathbf{0}$ & Adaptability & 14 \\
\hline 0.67 & 3.85 & $15 \%$ & 3 & $55 \%$ & 11 & $30 \%$ & 6 & 0.00 & $\mathbf{0}$ & 0.00 & $\mathbf{0}$ & $\begin{array}{l}\text { Familiarity and } \\
\text { inclusiveness }\end{array}$ & 15 \\
\hline $\mathbf{0 . 5 8}$ & 4.15 & $25 \%$ & 5 & $65 \%$ & 13 & $10 \%$ & 2 & 0.00 & $\mathbf{0}$ & 0.00 & $\mathbf{0}$ & $\begin{array}{l}\text { Professional } \\
\text { and scientific }\end{array}$ & 16 \\
\hline
\end{tabular}

Source: Prepared by the two researchers, depending on the outputs of the SPSS program

3.2 Presentation and analysis of the results of the evaluation of the proposed strategic document

Table (1) shows the arithmetic meanings and standard deviations that reflect the views of managers and experts in the company as follows:

1- Strategic analysis: Table (1) shows that strategic analysis has achieved a "very" high mathematical mean, reaching (4.25), in addition to "very high consistency" in the sample answers, as the standard deviation was (0.63), which reflects the extent of Accuracy and comprehensiveness of diagnosing internal and external environment factors, identifying strengths and weaknesses, opportunities and threats factors, and giving an accurate picture of the company's current reality.

2 - The vision: The results of the evaluation showed that the proposed vision was ambitious and that efforts and resources could be concentrated towards it, as it obtained a high arithmetic mean (4.05) and a standard deviation rate (0.68), which explains the existence of high agreement that it represented the image that the future can be imagined. During this period, its assets were derived from the past and present of the company and reflected the senior management's view of the future. 
3- The message: Table (1) reflects that the message expresses the philosophy and significance of the company's existence and clarifies its national identity, as the arithmetic average of the responses of the sample members reached (4.00) and a standard deviation coefficient (0.64). This represents high agreement and harmony by the sample. However, the message represented a source of inspiration and motivation for senior management and employees at an "equal" level, as well as realism, vitality and generality, allowing it to be used as a basis for clear and specific initiatives.

4- Values: The evaluation results resulted in that the values factor had obtained an arithmetic mean of the responses of the sample members amounted to (3.90) and a standard deviation coefficient (0.78), which represents the approval of the sample members on the values in the proposed strategy and that they represented standard principles in commitment towards achieving a vision The company's mission and its results are to achieve job satisfaction for employees, which creates a stimulating environment that raises morale and is reflected in their overall performance.

5- Strategic Objectives: The evaluation results indicated that the strategic objectives provided a direction towards higher priorities and a focus on the main activities of the company to ensure the optimal direction of resources in the direction that the company takes towards progress and development, as the strategic objectives factor obtained an arithmetic mean of (4.15) and a standard deviation It reached (0.67). This represents a high agreement and harmony on the part of the sample members that these goals are realistic and ambitious and will create a qualitative leap in the company's work.

6- Strategic issues: There is no doubt that each major activity has strategic issues that must be focused on because they represent the essence of the requirements of that activity. Table (1) shows that the strategic issues identified for each major activity in the proposed document have received a very high acceptance and approval, as the arithmetic mean reached $(4,20)$ and a standard deviation (0.69), which reflects consistency in the answers of the sample members.
7- Time span: In order for the basic elements of the strategic plan to be integrated, there must be a timeframe commensurate with the volume of activities required to be worked on, and the evaluation results indicated that the timeframe that has been set for achievement is appropriate and logical as this indicated the evaluation results and the responses of the sample members and their agreement on that The mean was (4.00) and a standard deviation (0.64).

8- Strategic alternatives: The strategic alternatives that have been proposed for each activity aim to advance the reality of that activity and when presenting these strategic alternatives to the sample members to evaluate them and consider whether they are correct and will advance the reality of the company's activities as a whole, the result was that these alternatives are correct and accurate and with very high agreement and harmony. It is high in the answers of the respondents, as the arithmetic mean was (4.30) and a standard deviation was (0.73).

9- Obstacles and limitations: For each activity or approach, there are obstacles and limitations that must be taken into account and work to avoid them or reduce their impact to the least possible extent, then proceed to accomplish this activity or orientation, and the researchers have identified a set of main limitations and obstacles for each activity in order to draw the attention of senior management to it and deal with it When presenting it for the evaluation, the results showed that the sample members agree highly on the existence of these obstacles, and the arithmetic mean was (3.90) and a standard deviation (0.71).

10- Programs: The proposed document included a set of programs aimed at organizing the plan's workflow as well as "distributing roles among the implementing agencies that achieve efficient use of the resources available to the company and these programs are consistent with the vision and mission of the company on the one hand and the technical, financial and administrative capabilities on the other hand and so forth. This is explained by the evaluation results and the high agreement that the sample members have with consistency in the answers. The mean is (4.10) and a standard deviation (0.71). 
11- Procedures: The programs in the proposed document included a set of procedures in predetermining the steps that must be followed to implement the work and its sequence to achieve the goals of the company, which were formulated as a means to achieve effectiveness in performance, and the results showed when the sample members evaluated them for consideration and evaluation that there are Aley agreed that they represented clear and uncomplicated steps that were characterized by ease of implementation and are subject to change and evaluation according to need. The mean was (3.90) and a standard deviation (0.71).

12- Success indicators: The two researchers put in the proposed strategic document a set of success indicators within each strategic issue and the main activity of the company, as these indicators were formulated based on the nature of the objectives that have been identified to represent, thus, criteria for measuring the extent to which the objectives are achieved and implemented, and the results of the evaluation of the sample members for this The indicators are highly consistent with the answers, and the mean is (3.90) and the standard deviation is (0.71).

13-Flexibility and response: There is no doubt that environmental changes are continuing, especially in the Iraqi environment and its dynamism, which requires willingness and speed to respond to these changes for the purpose of mobilizing resources in new directions. The proposed document has been formulated to be flexible and responsive to the changes that may arise, which requires the introduction of Modifications to it to suit the nature of the surrounding circumstances, and that agreement was confirmed in the answers of the sample members, as the arithmetic mean reached (3.90), which is a high value and the standard deviation (0.64).

14- Adaptability: The results of the evaluation showed that the proposed document has the adaptability to the environmental factors imposed by high agreement among the sample members, as the arithmetic mean was (4.10) and the standard deviation was (0.71).

15- Familiarity and comprehensiveness: In light of the need for good preparation for the future of the company and the development of the optimal vision for what it should be in order to overcome the obstacles that may be encountered and draw a better future for it, since the proposed plan was formulated to be comprehensive for the main joints and activities in order to be able to achieve a qualitative leap in the company's work In the sample's evaluation of the plan, it was found that there is high agreement that it enjoys the required familiarity and comprehensiveness, as the arithmetic mean was (3.85) and the standard deviation (0.67).

16- Professional and scientific: The two researchers were keen to have the highest levels of professionalism and science in all stages and steps of formulating the proposed strategy through honesty, impartiality and accuracy in dealing with information and data related to the company and respecting opinion and other opinion, as well as applying the latest scientific tools and methods and employing them in formulating a plan A strategy according to a scientific approach, and there was a high agreement that the proposed document was according to a professional and scientific approach, as it reached the arithmetic mean (4.15) and the standard deviation (0.58).

\subsection{Factors of the proposed strategic document by standard deviation}

Through Table (2) the researchers wanted to determine which of the factors of the proposed strategy had obtained a level of agreement and consistency more than other factors in the answers of the sample members, that is, a determination of which factor was dispersion and divergence in the answers of the sample members from the arithmetic mean of the answers. The factors according to the most consistent, in which the standard deviation is less than others, are as follows: 
Table (2) ranking of factors according to standard deviation

\begin{tabular}{|l|l|l|}
\hline $\begin{array}{l}\text { standard } \\
\text { deviation }\end{array}$ & The Worker & $\mathrm{d}$ \\
\hline 0.58 & Professional and scientific & 1 \\
\hline 0.63 & Strategic analysis & 2 \\
\hline 0.64 & the message & 3 \\
\hline 0.64 & Time span & 4 \\
\hline 0.64 & Flexibility & 5 \\
\hline 0.67 & strategic goals & 6 \\
\hline 0.67 & Familiarity & 7 \\
\hline 0.68 & Vision & 8 \\
\hline 0.69 & Strategic issues & 9 \\
\hline 0.71 & Constraints and limitations & 10 \\
\hline 0.71 & Programs & 11 \\
\hline 0.71 & Measures & 12 \\
\hline 0.71 & Indicators of success & 13 \\
\hline 0.71 & Adaptability & 14 \\
\hline 0.73 & Strategic alternatives & 15 \\
\hline 0.78 & Values & 16 \\
\hline
\end{tabular}

It is evident from Table (2) that the professional and scientific factor has obtained a standard deviation (0.58), which is the lowest percentage of dispersion and variation in the answers of the sample members among the factors that must be available in the proposed document, which can explain that this factor was the percentage of agreement Accordingly, in the proposed document, it is very high, followed by the strategic analysis factor, which achieved a very high level of consistency. The standard deviation was (0.64) for both "of them also", followed by flexibility and response, and the standard deviation was (0.64), and the strategic goals obtained high approval, as the standard deviation reached (0.67). As for familiarity and comprehensiveness, approval was obtained. With consistency and homogeneity in the answers of the sample members, as the standard deviation reached (0.67), and the vision obtained high approval, as the standard deviation reached (0.68). , 69), then the proportion of variation and dispersion in Afra's answers began The sample was more than (0.70) and this was evident in their responses to the factors (obstacles and limitations, programs, procedures, indicators of success, adaptability). Although they all obtained approval and in good proportions, the percentage of consistency and homogeneity in the answers of the sample members was More than the previous factors, as the standard deviation of all of them reached $(0,71)$. As for the strategic alternatives, they obtained a good percentage of agreement and harmony in the answers. Among the factors of the proposed document, the standard deviation was (0.78).

THE FOURTH AXIS: CONCLUSIONS AND RECOMMENDATIONS

4.1 Conclusions 
After reviewing the research sample about the proposed strategic document and the most important strategic issues that it contained and which they originally contributed to formulating it, as their opinion was that it represents a good opportunity in the event of its application to be a main nucleus to be a roadmap towards the progress and growth of the company and increase production and material and non-material resources and it is characterized by realism It covered the most important main activities of the company and diagnosed the most important obstacles and developed promising alternatives. The evidence for this is the results of the statistical analysis of the questionnaire that was distributed to them and proved that the proposed strategic document had an acceptance rate of $80 \%$.

\subsection{Recommendations}

\section{REFERENCES}

1. Al-Amiri, Salih Mahdi, Al-Ghalibi, Taher Mohsen (2011) Management and Business, 3rd Edition, Wael Publishing House, Amman, Jordan.

2. Al-Damour, Mowafak Muhammad (2008) The Reality of Strategic Planning for Human Resources in the Public Sector in Jordan, PhD Thesis in Business Administration / College of Financial and Banking Sciences, Arab Academy for Banking and Financial Sciences.

3. Khader, Majd (2016) The Concept of Strategy, the electronic journal of the Arab Forum for Human Resources Management, p. 174.

4. Emeka, , Nnamani, E.P. Ejim, Amaka, Ozobu (2015) "Effect of Strategy Formulation on Organizational Performance:A Study of Innoson Manufacturing Company Ltd Emene, Enugu, World Journal of Management and Behavioral Studies 3 (1).

5. Belyh, Anastasia(2017), Steps to Strategy Formulation, British Journal of Guidance \& Counselling.

6. Wheelen, Thomas L. , Hunger, J. David, Hoffman, Alan N. \& Bamford, Charles E. (2018), Conceptsin Strategic Management and Business Policy. 15 th, Printed and bound by Vivar in Malaysia

7. Bolisani , Ettore \& Bratianu, Constantin (2018), Knowledge and strategy formulation in a turbulent world , Cham: Springer International Publishing.

8. Bryson, John M,( 2004), Strategic Planning for Public and Nonprofi t Organizations, 3rd ed. San Francisco: Jossey-Bass.

9. Poister, Theodore H., (2010), The Future of Strategic Planning in the Public Sector: Linking Strategic Management and Performance, Public Administration Review, in the United States

10. Markides, Constantinos (1999), Six Principles of Breakthrough Strategy, Business Strategy Review, 1999, Volume 10 Issue 2.

11. Joshi, a., Kale, s., Chandel, s., \& Pal, D., K, (2015), Likert Scale: Explored and Explained ,British Journal of Applied Science \& Technology,7(4),396-403.

12. ALBU, RICARDO \& KRIST, ROBERT (2017) 6 Guiding Principles to Successful Strategy Management, Quarterly bulletins Albu Consulting Company 